\title{
Uma proposta de metodologia para a análise de histórias em quadrinhos
}

\author{
A methodology proposal for the analysis of comic books
}

1 Márcia Tavares Chico marciatch@gmail.com

1 Doutoranda em História pela Universidade Federal de Pelotas.

\section{Resumo}

O presente trabalho tem como objetivo sugerir uma proposta de metodologia para análise de histórias em quadrinhos. 0 artigo divide-se em duas seções. A primeira trata da apresentação da proposta de metodologia, a qual divide-se em análise estrutural, análise contextual e análise qualitativa. A subseção de análise estrutural lida com os elementos constituintes de uma história em quadrinhos, como os balões de fala, os painéis e o uso de cores. A análise contextual divide-se em dois momentos: análise do contexto interno e do contexto externo. A última subseção apresenta a análise qualitativa, trata da interpretação dos dados adquiridos nas duas análises anteriores sob o enfoque desejado pela/o pesquisadora ou pesquisador. A segunda seção traz um exemplo de análise, baseado na proposta feita, da HQ Eles nos chamavam de inimigo (2019), de autoria de George Takei em coautoria com Justin Eisinger, Steven Scott e arte de Harmony Becker. A HQ é uma obra biográfica e narra a história da família Takei pelos campos de concentração para nipo-americanas/os, nos Estados Unidos da América, durante a Segunda Guerra Mundial.

\section{Palavras-chave}

Histórias em quadrinhos. Metodologia. Proposta de análise.

\begin{abstract}
The present article aims to propose a methodology for the analysis of comic books. It is divided into two sections. The first section presents the proposed methodology, which is divided into structural analysis, contextual analysis, and qualitative analysis. The structural analysis subsection deals with elements present in comic books, such as speech bubbles, panels, and the use of color. Contextual analysis is divided into two moments: analysis of the internal context and of the external context. The last subsection, qualitative analysis, deals with the interpretation of the data acquired in the last two analyses under the focus proposed by the researcher. The second section presents an example of analysis, based on the proposed methodology, of the comic book They called us enemy (2019) written by George Takei and co-written by Justin Eisinger and Steven Scott, art by Harmony Becker. The comic book is biographical and narrates the story of the Takei family in concentration camps for JapaneseAmerican, in the United States of America, during World War II.
\end{abstract}

\section{Keywords}

Comic books. Methodology. Analysis proposal.

\section{Como você deve citar?}

CHICO, Márcia Tavares. Uma proposta de metodologia para a análise de histórias em quadrinhos. Cadernos UniFOA, Volta Redonda, n. 43, p. 121-131, abril 2020. 


\section{CONSIDERAÇÕES INICIAIS}

As histórias em quadrinhos (HQs), como as conhecemos hoje, tiveram seu início nas tiras de jornal norte-americanas no século XX (KAINDL, 2018). Os quadrinhos envolvem os mais variados estilos, apresentando desde histórias de mistério até biografias. Ao longo dos anos, eles foram vistos de diversas maneiras pelo público e crítica: alguns viam as histórias em quadrinhos como mero entretenimento, sem valor analítico ou cultural; outros, como histórias infantis, as quais não poderiam ser lidas por adultos, pois seriam simples demais; outros, ainda, alegavam que as histórias em quadrinhos eram responsáveis pela alienação e violência dos jovens - o que levou ao ato de censura dos quadrinhos conhecido como Comics Code Authority (GARCÍA, 2012).

Apesar das opiniões, muitas vezes contrárias, os quadrinhos vêm adentrando a academia. As análises, sob as mais variadas lentes, vêm sendo feitas no Brasil, pelo menos desde a década de 70, com os estudos semióticos de Antonio Luiz Cagnin (republicados pela Editora Criativo, em 2014). Atualmente os quadrinhos são analisados nas mais diversas áreas, com estudos que contemplam desde a análise histórica, enfocando tanto o período em que foram escritos quanto o período que representam, até pesquisas sob o viés dos estudos de gênero.

No entanto, metodologias para a análise de histórias em quadrinhos ainda são poucas e, por vezes, específicas a um tipo de área do conhecimento. Pensando nisso, e na minha própria dificuldade de encontrar uma metodologia para quadrinhos que se encaixasse com minha pesquisa ${ }^{2}$, o presente artigo tem como objetivo propor uma metodologia para análise de histórias em quadrinhos. Não pretendo apresentar algo muito complicado, mas sim uma metodologia simples e que possa ser expandida e melhorada por outras/os pesquisadoras/es.

O artigo é dividido em duas partes: a primeira será a apresentação da metodologia, com explicações básicas sobre cada etapa; já a segunda, será um exercício de análise de uma história em quadrinhos utilizando a metodologia proposta. Para a análise, foi escolhido o HQ Eles nos chamavam inimigo, de autoria de George Takei, com coautoria com Justin Eisinger, Steven Scott e arte de Harmony Becker.

\section{PROPOSTA DE METODOLOGIA}

A metodologia que aqui proponho divide-se em três etapas: a primeira etapa constitui uma análise estrutural da $\mathrm{HQ}$; a segunda etapa apresenta uma análise contextual da obra, tanto do contexto interno quanto do contexto externo; e a terceira e última parte tem como objetivo a junção das duas etapas anteriores para a realização de uma consideração qualitativa.

\subsection{Análise estrutural}

A primeira etapa, a da análise estrutural da $\mathrm{HQ}$, leva em consideração os aspectos visuais e estéticos da obra. Não se trata de uma análise geral do quadrinho, tendo de ser realizada para cada imagem que a pesquisadora ou o pesquisador decidir utilizar.

Não há, atualmente, uma única definição do que vem a ser um quadrinho. No entanto, uma das definições mais aceitas é a de arte sequencial, do teórico e quadrinista Will Eisner. Para o autor, uma história em quadrinho se destaca pela utilização de uma conexão entre a imagem e a linguagem escrita:

2 Minha pesquisa trata da representação do feminino nas obras em quadrinhos do escritor britânico Alan Moore. 
é a união entre texto e imagem, utilizada de forma complementar e não redundante, capaz de apresentar a história que é lida a partir de uma sequência de imagens específica (EISNER, 1985).

Segundo o autor, "os regimes da arte (por exemplo, perspectiva, simetria, pincelada) e os regimes da literatura (por exemplo, gramática, enredo, sintaxe) tornam-se superimpostos uns com os outros" 3 (EISNER, 1985, p. 8, tradução minha).

Assim, apresentarei alguns elementos estruturais da narrativa que acredito serem importantes para a análise de histórias em quadrinhos.

Tabela 1 - Elementos estruturais

\begin{tabular}{ll}
\hline Balão & $\begin{array}{l}\text { De fala } \\
\text { De pensamento }\end{array}$ \\
\hline Legenda & Título \\
\hline Outros elementos linguísticos & A tipografia do texto dos diálogos \\
& Inscrições \\
& Onomatopeias \\
\hline Painéis & Estilização \\
\hline Uso de cores & Plano médio \\
\hline Enquadramento & Plano aberto \\
& Plano fechado \\
& Primeiríssimo primeiro plano \\
\hline Ângulo & Etc. \\
\hline Nersonagens & Plongée \\
& Contra plongée \\
\hline & Etc. \\
\hline & Expressões \\
& Posição \\
& Vestimentas \\
\end{tabular}

FONTE: autoria minha.

Essa não é uma lista exaustiva, mas apresenta, na minha opinião, os principais elementos a serem analisados em uma história em quadrinhos pois, além de serem características das HQs, são essenciais para o entendimento da obra. É importante lembrar, obviamente, que nem todos esses elementos serão usados em uma cena ou, até mesmo, em toda a história. Por isso, há necessidade de se analisar cada imagem individualmente.

\subsection{Análise contextual}

As histórias em quadrinhos são artefatos culturais e históricos. Elas são construídas dentro de um contexto de produção específico, apresentando valores e ideias presentes na sociedade da época. Segundo Natania Nogueira,

3 No original: "the regimens of art (eg. perspective, symmetry, brush stroke) and the regimens of literature (eg. grammar, plot, syntax) become superimposed upon each other". 
as histórias em quadrinhos se adaptaram e se integraram ao contexto histórico no qual estavam inseridas, sendo que os personagens e os enredos se tornam expressões dos anseios, valores, preconceitos e mesmo das frustrações de seus criadores, eles mesmo produtos de sua época. Nos quadrinhos estão as representações do real, ou daquilo no que se deseja transformar a realidade (NOGUEIRA, 2010, p. 2).

Mesmo que uma HQ trate de um momento histórico diferente daquele em que foi produzida, ela o faz a partir do olhar que a criadora ou o criador possui, o qual é baseado no momento em que a obra está sendo criada. Assim, é importante analisarmos dois aspectos no que tange ao contexto: 0 contexto interno e o contexto externo.

O contexto interno trata do momento que está sendo representado na obra, que pode, ou não, ser o mesmo que o contexto externo. Temos HQs que representam o passado, outras o presente, outras ainda representam o futuro; ou, até mesmo, uma mistura de todos esses momentos. 0 contexto interno da obra vai nos mostrar como entender os rumos da narrativa e as ações e acontecimentos da história. Também irá nos mostrar como devemos nos portar para o entendimento da trama: o que está sendo representado pode, por exemplo, ser um evento histórico que realmente aconteceu e que é exposto de forma biográfica; um momento inventado do passado, que não tem base histórica - o mesmo se dá com momentos futuros; ou uma nova representação de um evento histórico, com este sendo repensado de acordo com o gênero da história - como, por exemplo, narrativas steampunk.

O contexto externo, por sua vez, trata do período de produção da obra. Por mais que representemos um momento histórico, fazemos isso através do olhar do presente em que nos encontramos. Uma obra pode ser produzida porque as/os criadoras/es acham que ela possa ser importante para a época em que se encontram, que seja representativa, que faça uma denúncia de algo que aconteceu ou que está acontecendo, dentre várias outras possibilidades. Ao analisarmos o contexto externo de uma obra, também podemos entender melhor o contexto interno.

\subsection{Análise qualitativa baseada nos dados}

Por último, temos a etapa da análise qualitativa baseada nos dados recolhidos nas duas etapas anteriores. Uma análise de quadrinhos não pode ser somente estrutural ou contextual, pois precisa juntar todos os elementos e construir uma interpretação do que foi averiguado. Por exemplo, ao analisar uma obra, vimos que a personagem que escolhemos apresenta um formato de balão diferenciado das demais personagens. Esse dado por si só é interessante, mas não nos ajuda a de fato compreender a obra. No entanto, a partir da constatação de que o balão é diferente, podemos chegar a algumas conclusões: a autora ou o autor do texto desejou, por algum motivo a ser explicitado ou não na obra, destacar aquela personagem, mostrando que ela não é igual aos demais; o balão pode mostrar, também, a maneira como a personagem fala, mostrando à leitora ou ao leitor como perceber a voz daquela personagem, já que o som não pode ser representado em um quadrinho.

Nessa etapa, poderemos escolher a bibliografia a ser utilizada para análise de acordo com o enfoque que queremos. Podemos fazer, por exemplo, uma análise historiográfica ou uma análise de gênero e sexualidade.

\section{UMA BREVE APLICAÇÃO DA PROPOSTA}

Para aplicar a metodologia proposta, conforme já explicitado, escolhi a HQ biográfica Eles nos chamavam de inimigo, escrita por George Takei, com coautoria com Justin Eisinger e Steven Scott, e arte de Harmony Becker. A HQ narra a história da família Takei, cidadãos americanos que, durante a Segunda Guerra Mundial, foram forçados, por serem de origem japonesa, a viver em campos de concentração para 
nipo-americanos. George Takei ficou famoso por interpretar Hikaru Sulu na série de televisão de 1966, Star Trek (conhecida no Brasil como Jornada nas Estrelas), e subsequentes séries e filmes da franquia. A HQ alterna entre o passado, a história da família, e o presente, com George contando sua história.

Para a análise, foram escolhidas duas cenas: na primeira, o prefeito de Los Angeles fala a favor dos campos de concentração para nipo-americanas/os; na outra, o pai de George tenta acalmar o filho, em rumo a um campo de concentração, dizendo que eles estão saindo de férias.

\subsection{Análise estrutural}

A primeira cena a ser analisada traz dois momentos complementares. Em um, mãe e filha de origem japonesa passam em frente a uma loja que não permite a entrada de japonesas/es. Já no outro momento, o prefeito de Los Angeles fala sobre a impossibilidade de assimilação desse grupo à sociedade americana. Vejamos a Figura 1:

Figura 1 - Reações às/aos nipo-americanas/os. @ George Takei, 2019. Todos os direitos reservados.

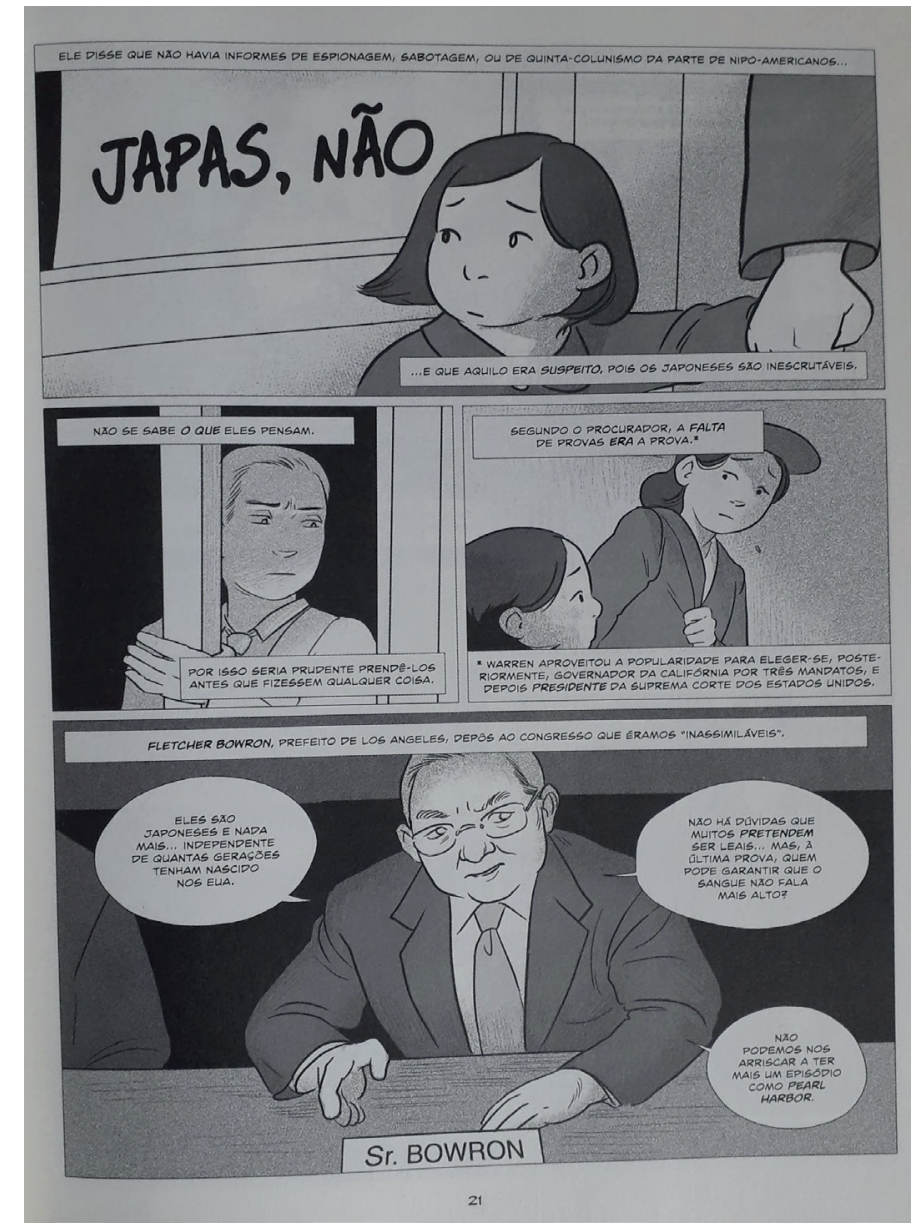

Fonte: TAKEl et al., 2019, p. 21.

A história toda é narrada em preto e branco. Também podemos perceber que os desenhos são simples, sem muitos detalhes. As personagens estão usando roupas normais, do dia a dia, ou um terno, no caso do prefeito. 
Temos quatro personagens diferentes: um dono de loja, uma mãe e filha japonesas, e o prefeito de Los Angeles. $O$ dono da loja apresenta uma expressão desconfiada; a filha parece confusa, enquanto a mãe tem uma expressão de tristeza; já o prefeito parece confiante naquilo que está dizendo.

Todos os painéis da página apresentam legendas, nas quais George Takei narra os sentimentos dos americanos em relação aos japoneses após o ataque a Pearl Harbor. O prefeito possui balões de fala, os quais retratam a sua visão sobre a "assimilação" dos japoneses à sociedade americana. Temos duas inscrições: um cartaz com "Japas não" na frente de uma loja e o nome do prefeito em uma placa a sua frente. Os painéis são simples e sem estilização.

O prefeito é retratado em meio primeiro plano - da cintura para cima - e em ângulo frontal. A filha e o dono da loja são representados em primeiro plano - do peito para cima, em ângulo normal. A mãe e a filha estão em um ângulo contra plongée - de baixo para cima - seguindo a direção do olhar da filha para a mãe.

Passamos agora para a Figura 2:

Figura 2 - nipo-americanas/os em direção a um campo de concentração. () George Takei, 2019. Todos os direitos reservados.

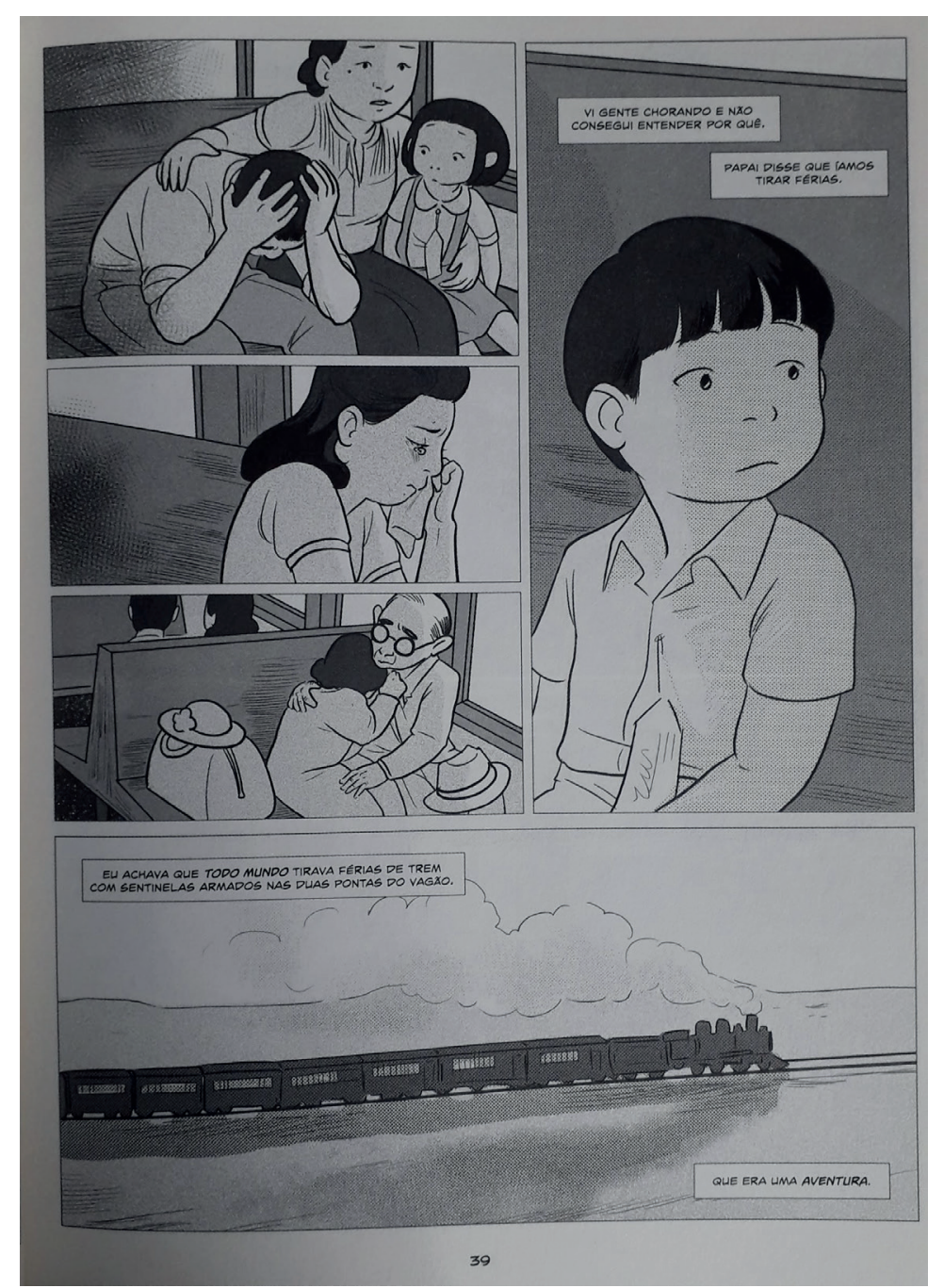

Fonte: TAKEl et al., 2019, p. 39. 
Quando perguntado sobre para onde estavam indo, o pai de George responde que eles estavam saindo de férias. O pequeno George fica feliz com a perspectiva, mas começa a analisar as outras pessoas que também estão no trem. Temos, então, o foco voltado para a perspectiva de George sobre a situação. Como na Figura 1, também temos legendas com a narração do George Takei no presente sobre o que estava acontecendo.

Novamente, os traços são simples, sem muitos detalhes. Vemos George, uma família de três pessoas, um casal e uma mulher sentada sozinha com um lenço. Em todas as personagens - com a exceção de George e da criança da primeira família que demonstram confusão - podemos ver tristeza e desolação com a situação em que se encontram.

Temos quatro painéis, sendo o último um plano geral do trem em que as personagens se encontram. Nos outros painéis, temos George, em ângulo $3 / 4$ e meio primeiro plano; enquanto os outros painéis apresentam as personagens em ângulo $3 / 4$ ou perfil, como no caso da moça sentada sozinha, $\mathrm{e}$ plano americano ou primeiro plano.

\subsection{Análise contextual}

Primeiramente, analisarei o contexto interno da obra.

Em 7 de dezembro de 1941, a Marinha Imperial Japonesa realizou um ataque aeronaval a base americana de Pearl Harbor, na ilha de Oahu, no Havaí. Pearl Harbor se tornou um "ícone proeminente na história dos Estados Unidos" evocando "imagens de guerra e como esses anos afetaram profundamente a vida dos americanos"4 (YOO, 1996, p. 680, tradução minha).

Após o ataque, cidadãs/ãos nipo-americanas/os foram acusadas/os de espionagem e sabotagem, levando a um episódio importante das consequências do ataque a Pearl Harbor: o encarceramento de nipo-americanas/os em campos de concentração, ilustrando o contraste entre a luta pela liberdade e democracia fora do país e as relações de raça dentro do país (YOO, 1996).

A retirada de direitos dados às/aos cidadãs/ãos nipo-americanas/os foi resultado da Ordem Executiva 9066, de 19 de fevereiro de 1942, a qual fez com que mais de 120.000 nipo-americanas/os fossem aprisionadas/os em campos de concentração existentes em território americano.

A HQ Eles nos chamavam de inimigo conta a história biográfica de George Takei e de sua família em passagem por diversos campos de concentração e a confusão das crianças sobre o que estava acontecendo. Os eventos são narrados por um Takei do presente, que entende o que realmente aconteceu e as consequências que o aprisionamento teve em sua vida, na vida de sua família e na vida de milhares de outras/os nipo-americanas/os.

A HQ também faz referência a acontecimentos do tempo presente, como a proibição da entrada de imigrantes muçulmanas/os nos Estados Unidos e a aparição de "afrontas antigas (...) com resultados brutais" (TAKEl et al., 2019, p. 197), aludindo aos campos de concentração para imigrantes. Isso nos leva ao contexto externo da obra.

4 No original: "a prominent icon in United States history, Pearl Harbor evokes images of war and how these years deeply affected the lives of Americans." 
Em 2016, Donald Trump foi eleito presidente dos Estados Unidos, tomando posse em janeiro de 2017. Em seu governo, estabeleceu políticas duras contra imigrantes, principalmente imigrantes ilegais, mas também imigrantes legais.

Em 2018, a administração Trump lançou um programa de tolerância zero e o Departamento de Justiça, em maio do mesmo ano, começou a processar imigrantes que tentavam cruzar a fronteira ilegalmente, "focando principalmente em imigrantes que viajavam com crianças 5 " (SWANSON, 2018, p. 177, tradução minha). Essa prática foi abolida em junho de 2018, mas centenas de crianças ainda continuam separadas de suas famílias (SWANSON, 2018). No entanto, a prática de encarceramento de imigrantes continua. Estima-se que existam, hoje, 38 mil pessoas detidas em 200 campos de concentração espalhados pelos Estados Unidos (SWANSON, 2019).

As condições nos campos são terríveis, incluindo trabalho forçado, consumo de alimentos estragados, falta de mantimentos básicos para higiene e de roupas adequadas ao clima (SWANSON, 2019; PELLOW, VANZIN, 2019). Segundo Pellow e Vazin, as/os imigrantes detidos nos campos de concentração, muitos sem ser acusados formalmente de nenhum crime pelo governo americano, são sujeitas/os a condições abusivas e contaminação ambiental, o que já resultou em mortes (PELLOW; VAZIN, 2019). Muitos desses campos são construídos em solo contaminado por poluentes, sejam advindos de testes militares ou tratamento de água, apresentado toxinas nocivas à saúde humana (PELLOW; VAZIN, 2019).

Além de serem forçados a experienciar condições inumanas e serem expostos a diversos poluentes, às/aos imigrantes é negado o direito a tratamento médico (SWANSON, 2019; PELLOW, VAZIN, 2019).

\subsection{Análise geral}

Passarei, agora, para uma breve análise da $\mathrm{HQ}$, utilizando os elementos elencados nas etapas anteriores.

O uso de preto e branco em quadrinhos é uma escolha comum em HQs biográficas para que o foco seja a história em si, a mensagem passada através da história de vida da personagem. Na narrativa, isso é somado à simplicidade dos traços, o que faz com que o foco da leitora ou do leitor fique presente nos acontecimentos e na carga emocional atrelada a eles. A simplicidade também está demonstrada nos ângulos e enquadramentos utilizados. Nas imagens analisadas, são mostradas as personagens em ângulos em que é possível ver sua expressão facial ou sua linguagem corporal.

Na Figura 1, em um momento, temos um ângulo contra plongée. No entanto, diferentemente de seu uso normal, não aumenta as personagens ou as engrandece. Pelo contrário, o ângulo nos permite seguir o olhar confuso da menina e a tristeza que pode ser vista no rosto de sua mãe. Assim, somos convidados a partilhar a tristeza da mãe, sua impotência em proteger sua filha dos ataques, mesmo que simbólicos, cometidos contra as/os nipo-americanas/os. Também podemos ver a confusão da menina, sendo levados a enxergar o mundo pelo olhar da criança, compartilhar seu sofrimento e confusão.

Isso vai ao encontro da noção de Mitchell de que as imagens - principalmente as pinturas, mas acredito que podemos trazer a ideia para o campo dos quadrinhos também - têm o desejo de paralisar, de "emocionar e mobilizar o espectador" (MITCHELL, 2015, p. 175), pois a simplicidade das imagens utilizadas não diminuem o impacto, mas sim o aumentam.

5 No original: "... focusing primarily on immigrants traveling with children." 
Ainda na Figura 1, temos em forma de uma inscrição a frase "Japas não" (TAKEl et al., 2019, p. 21, painel 1). Isso nos ajuda a entender como era o dia a dia das/os cidadãs/ãos nipo-americana/os e o tipo de preconceito que enfrentavam ao sair de casa. A frase explicitada deixa claro que a população nipo-americana estava sendo separada do resto da comunidade, vista como o inimigo, como aqueles que devemos temer ou desconfiar - também expresso pelo olhar do dono da loja, no segundo painel da Figura 1.

Segundo Gruzinski, "a imagem torna-se um interlocutor e, se não uma pessoa, pelo menos uma força com a qual se negocia e barganha" (GRUZINSKI, 2006, p. 227). A HQ, nesse caso, é um meio que negocia e barganha significado através da imagem, mas não só isso. A HQ constrói o seu significado a partir da junção, não redundante como vimos anteriormente, do conteúdo imagético e da linguagem verbal. Através de seus mais variados elementos, a $\mathrm{HQ}$ se torna uma interlocutora, conversando com quem a lê, negociando significado através da bagagem de conhecimentos da leitora ou leitor.

Na Figura 2, podemos ver a confusão na expressão do menino George, que não entende o que está acontecendo. Por um lado, seu pai diz que estão saindo em férias; por outro, as pessoas a sua volta estão chorando ou apresentando expressões desoladas. Tal confusão vem conectada à legenda, que diz: "Eu achava que todo mundo tirava férias de trem com sentinelas armados nas duas pontas do vagão. Que era uma aventura" (TAKEl et al., 2019, p. 39). O pequeno George não entende o que está acontecendo, a significância do momento, a retirada de direitos sofrida por sua família e por todas as outras pessoas no trem. Para ele, tudo é uma aventura, e que ser vigiada/o por guardas armados era algo normal que acontecia com toda/os aquela/es que saíam de férias. Somente mais tarde é que ele entenderá o que realmente se passou.

Segundo Hall, não podemos falar de identidade, mas de identidades: não possuímos um "eu" fixo, mas sim um "eu" em constante mudança e (re)construção (HALL, 2015). Assim, não podemos atrelar uma única identidade para uma nação ou para uma parcela da população. No caso da $\mathrm{HQ}$, não podemos ver todas/os cidadãs/ãos nipo-americana/os como possuidoras/es das mesmas características identitárias.

No entanto, agindo por causa dos acontecimentos de Pearl Harbor, o governo americano tentou formar uma única identidade ao redor das/os nipo-americanas/os: a identidade de inimigo. Na Figura 1, podemos ver o prefeito de Los Angeles, Fletcher Bowron, falando para a imprensa que as/os nipo-americanas/os eram "inassimiláveis". Segundo ele, não importava quantas gerações essas pessoas estivessem nos Estados Unidos, elas continuariam sendo diferentes, sendo japonesas. Tal ideia levou à criação de campos de concentração, pois não se podia confiar em japonesas/es; era necessário evitar que Pearl Harbor se repetisse, como diz o prefeito no último painel da Figura 1.

Hall também nos diz que "a identidade muda de acordo com a forma como o sujeito é interpretado ou representado" (HALL, 2015, p. 16), o que, na HQ, faz com que a identidade nipo-americana gire em torno de uma concepção representativa de inimigo, daquele que não é de confiança e que precisa ser retirado do resto da sociedade, tanto pelo bem do restante da população como para seu próprio bem, pois por mais que queiram ser leais, como diz Bowron na Figura 1, o sangue pode falar mais alto. Assim, uma identidade nipo-americana é criada, ignorando o fato da identidade ser multifacetada.

Para Mitchell, as imagens não são uma visão transparente de nossa realidade, pois trazem, em si, uma ideologia, um "mecanismo de representação6 " (MITCHELL, 1986, p. 8, tradução minha). Levando em consideração o momento de produção, acredito ser possível dizer que a HQ não foi publicada somente para narrar uma história ou apresentar uma biografia. Ela foi criada com o intuito de mostrar pelo que passaram as/os cidadãs/ãos nipo-americanas/os durante a Segunda Guerra Mundial, na qual o

6 No original: "mechanism of representation." 
preconceito e o medo fizeram com que os direitos de milhares de pessoas fossem retirados. Também foi criada para chamar a atenção das/os leitoras/es para o fato da mesma situação estar se repetindo na atualidade, com milhares de pessoas encarceradas em campos de concentração por causa de seu local de origem, sua religião ou sua cor de pele. Takei et al. (2019) tentam traçar um paralelo entre os campos de concentração de ontem e os de agora para representar um sofrimento tanto passado quanto presente.

\section{CONSIDERAÇÕES FINAIS}

O presente artigo teve como objetivo a apresentação de uma proposta de metodologia de análise de histórias em quadrinhos, a qual pode ser modificada, expandida ou melhorada em outros artigos ou por outras/os pesquisadoras/es. Assim, apresentei, primeiramente, a minha proposta e, depois, uma breve análise para mostrar a metodologia em uso.

Procurei trazer uma metodologia básica e fácil de ser utilizada, que leve em consideração tanto a parte escrita quanto a parte imagética das histórias em quadrinhos, além dos contextos interno e externo da obra. Sendo assim, a metodologia possui três etapas: a primeira trata de uma análise de critérios estruturais, como enquadramento, uso de cores, etc; a segunda etapa traz uma análise dos contextos internos e externos da obra; enquanto o terceiro momento se ocupa de uma análise qualitativa, que se utiliza dos dados das fases anteriores, sendo feita uma interpretação da obra que está sendo analisada.

Para demonstração da metodologia, foi utilizada a HQ Eles nos chamavam de inimigo, de autoria de George Takei, Justin Eisinger, Steven Scott e arte de Harmony Becker. Analisando duas cenas específicas, procurei mostrar como tanto os elementos estruturais quanto os elementos conceituais foram fundamentais para o entendimento da obra.

\section{REFERÊNCIAS}

EISNER, Will. Comics and sequential art. Flórida: Poorhouse Press, 1985.

GARCÍA, Santiago. A novela gráfica. Tradução Magda Lopes. São Paulo: Martins Fontes, 2012.

GRUZINSKI, Serge. A guerra das imagens: de Cristóvão Colombo a Blade Runner (1492-2019). Tradução de Rosa Freire D'Aguiar. São Paulo: Companhia das Letras, 2006.

HALL, Stuart. A identidade cultural na pós-modernidade. Tradução de Tomaz Tadeu da Silva e Guacira Lopes Louro. Rio de Janeiro: Lamparina, 2015.

KAINDL, Klaus. Crás, tum, soc. Um modelo para o estudo de histórias em quadrinhos traduzidas. Tradução de Márcia Tavares Chico e Daniel Soares Duarte. Target, 2018.

MITCHELL, W.J.T. Iconology: image, text, ideology. Chicago: University of Chicago Press, 1985.

MITCHELL, W.J.T. O que as imagens realmente querem. In: ALLOA, Emmanuel (org.). Pensar a imagem. Belo Horizonte: Editora Autêntica, 2015.

NOGUEIRA, Natania. Representações femininas nas histórias em quadrinhos da EBAL. História, imagem e narrativas. No 10, abril/2010. p. 1-14. 
PELLOW, David; VAZIN, Jasmine. The Intersection of Race, Immigration Status, and Environmental Justice. Sustainability, v. 11, n. 14, jul/2019.

SWANSON, Kate. Silent Killing: The Inhumanity of U.S. Immigration Detention. Journal Of Latin American Geography, v. 18, n. 3, 2019. p.176-187.

TAKEl, George, et al. Eles nos chamavam de inimigo. Tradução de Érico Assis. São Paulo: Devir, 2019.

YOO, David. Captivating memories: museology, concentration camps, and Japanese American history. American Quarterly, vol. 48, n. 4, dezembro/1996, p. 680-699. 